\title{
Factors associated with psychological distress, fear and coping strategies during the COVID-19 pandemic in Australia
}

\author{
Muhammad Aziz Rahman ${ }^{1,2,3^{*}}$ (D), Nazmul Hoque ${ }^{3,4}$, Sheikh M. Alif ${ }^{3,5}$ (D) Masudus Salehin ${ }^{1}$ (D),

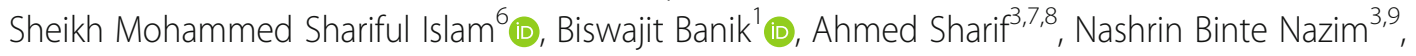 \\ Farhana Sultana ${ }^{10}$ and Wendy Cross $^{1}$ (D)
}

\begin{abstract}
Background: The COVID-19 pandemic disrupted the personal, professional and social life of Australians with some people more impacted than others.

Objectives: This study aimed to identify factors associated with psychological distress, fear and coping strategies during the COVID-19 pandemic in Australia.

Methods: A cross-sectional online survey was conducted among residents in Australia, including patients, frontline health and other essential service workers, and community members during June 2020. Psychological distress was assessed using the Kessler Psychological Distress Scale (K10); level of fear was assessed using the Fear of COVID-19 Scale (FCV-19S); and coping strategies were assessed using the Brief Resilient Coping Scale (BRCS). Logistic regression was used to identify factors associated with the extent of psychological distress, level of fear and coping strategies while adjusting for potential confounders.

Results: Among 587 participants, the majority (391, 73.2\%) were 30-59 years old and female $(363,61.8 \%)$. More than half $(349,59.5 \%)$ were born outside Australia and two-third $(418,71.5 \%)$ completed at least a Bachelor's degree. The majority $(401,71.5 \%)$ had a source of income, $243(42.3 \%)$ self-identified as a frontline worker, and 335 (58.9\%) reported financial impact due to COVID-19. Comorbidities such as pre-existing mental health conditions (AOR 3.13, 95\% Cls 1.12-8.75), increased smoking $(8.66,1.08-69.1)$ and alcohol drinking $(2.39,1.05-5.47)$ over the last four weeks, high levels of fear $(2.93,1.83-4.67)$ and being female $(1.74,1.15-2.65)$ were associated with higher levels of psychological distress. Perceived distress due to change of employment status (4.14, 1.39-12.4), alcohol drinking $(3.64,1.54-8.58)$, providing care to known or suspected cases $(3.64,1.54-8.58)$, being female $(1.56,1.00-2.45)$, being $30-59$ years old $(2.29,1.21-4.35)$ and having medium to high levels of psychological distress $(2.90,1.82-5.62)$ were associated with a higher level of fear; while healthcare service use in the last four weeks was associated with medium to high resilience.

(Continued on next page)
\end{abstract}

\footnotetext{
* Correspondence: ma.rahman@federation.edu.au; aziz.rahman@y7mail.com

${ }^{1}$ School of Health, Federation University Australia, 100 Clyde Road, Berwick, Victoria 3806, Australia

${ }^{2}$ Australian Institute of Primary Care and Ageing, La Trobe University, Plenty

Road and Kingsbury Drive, Melbourne, Victoria 3086, Australia

Full list of author information is available at the end of the article
}

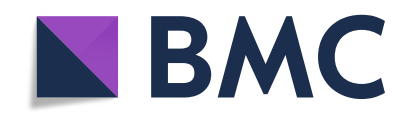

(c) The Author(s). 2020 Open Access This article is licensed under a Creative Commons Attribution 4.0 International License, which permits use, sharing, adaptation, distribution and reproduction in any medium or format, as long as you give appropriate credit to the original author(s) and the source, provide a link to the Creative Commons licence, and indicate if changes were made. The images or other third party material in this article are included in the article's Creative Commons licence, unless indicated otherwise in a credit line to the material. If material is not included in the article's Creative Commons licence and your intended use is not permitted by statutory regulation or exceeds the permitted use, you will need to obtain permission directly from the copyright holder. To view a copy of this licence, visit http://creativecommons.org/licenses/by/4.0/ The Creative Commons Public Domain Dedication waiver (http://creativecommons.org/publicdomain/zero/1.0/) applies to the data made available in this article, unless otherwise stated in a credit line to the data. 
(Continued from previous page)

Conclusions: This study identified individuals who were at higher risk of distress and fear during the COVID-19 pandemic specifically in the State of Victoria, Australia. Specific interventions to support the mental wellbeing of these individuals should be considered in addition to the existing resources within primary healthcare settings.

Keywords: COVID-19, Coronavirus, Mental health, Psychological distress, Coping, Resilience

\section{Introduction}

The coronavirus disease (COVID-19) had affected more than 213 countries and territories around the world with more than 28 million cases and nearly one million deaths as of mid-Sep-2020 [1]. In the same time frame, Australia reported over 25,000 confirmed cases and about 800 deaths from COVID-19 [2]. Although the case fatality rate was low in Australia compared to other developed countries such as USA or UK, people were distressed due to the nature of transmission (i.e. through direct or indirect contact) and the rapid spread within the communities, which radically changed regular lifestyles for most Australians [3].

In order to limit the spread of COVID-19, the Australian Government introduced physical distancing rules including restrictions on social gatherings, strict lockdowns, and border closures with a pause on all social, cultural and sporting activities [2]. These restrictions were likely to have tremendous impact on the social, psychological and economic wellbeing of Australians living through this pandemic [4]. Strict border closures and physical distancing measures played a crucial role in reducing the spread of community transmission resulting in a 'flattening of the curve' from late March to mid-June 2020. However, Australia has faced a second wave of pandemic with the highest increase of daily case number of more than 700 in the state of Victoria in early August 2020 [2]. Many small businesses were closed due to the imposed restrictions from late March 2020 and the unemployment rate increased to $15 \%$ in June 2020 compared to $9 \%$ in June $2019[4,5]$. Stricter restrictions and night-time curfews were implemented in the State of Victoria solely to curb the spread of infection. The continued impact of restrictions and the uncertainty around going back to normal were likely to affect personal and social life as well as mental wellbeing of all Australians [4]. Ongoing restrictions were likely to impact physical health as well, specifically those with chronic diseases. Health care seeking behaviour was also affected by the COVID-19 pandemic, as patients limited their in-person visits to their general practitioners (GPs) to avoid the possible risk of transmission from suspected/asymptomatic cases of COVID-19 and have started to access telehealth facilities [6]. Moreover, social isolation, along with uncertainty in employment status could have triggered risky behaviours such as increased smoking and alcohol intake [4].

Frontline workers including the health care workers were at increased risk of infection during the COVID-19 pandemic. Evidence suggests that frontline healthcare workers, who were directly involved in the collection of samples, diagnosis, treatment, and care of patients during an outbreak, were also at higher risk of developing psychological distress and mental health symptoms [7]. Anxiety, distress, depression, fear of spread of infection to family, friends and colleagues, anger and confusion were some of the immediate psychological impacts documented among frontline healthcare workers $[4,8]$. Ongoing restrictions, uncertainty of returning to normal life and deaths that were avoidable under usual circumstances were also likely to increase people's risk of developing long-term mental health issues [9]. It was, therefore, important to understand the extent of the mental health burden in communities during the COVID-19 pandemic in Australia. This study will assist in designing appropriate psychosocial interventions and will provide a baseline against which such interventions could be assessed.

Evidence examining factors associated with psychological distress and fear due to the COVID-19 pandemic in Australia was limited. A recently published study suggested that increased psychological distress was more common among middle-aged single women and mothers, and those in lower-income categories [4]. Prior evidence suggested that lack of sleep, increased smoking and alcohol intake were associated with higher levels of depression, anxiety and stress during the pandemic [8]. Another study found that psychological distress was associated with self-reported mood disorder and lifestyle changes [3]. However, evidence-based evaluations on psychological distress, fear and coping strategies were relatively scarce [8]. To address this gap, the aim of the current study was to (a) Assess the extent of psychological distress and the level of fear of COVID-19 among residents in Australia, and (b) Identify coping strategies and key factors associated with psychological distress, fear and coping during the pandemic period.

\section{Materials and methods}

\section{Study design and settings}

This anonymous cross-sectional study was hosted on the online platform Qualtrics and distributed using social media (Facebook, Messenger, Twitter and LinkedIn), text messages and emails. Participants were recruited from GP and Allied Healthcare settings, and community 
groups via the online platform across all states and territories in Australia between 1st and 30th June 2020.

\section{Study population}

Australian residents aged $\geq 18$ years and capable of responding to an online questionnaire in English were invited to participate. Study participants included (a) patients who attended a general practice or an allied healthcare setting, either for face-to-face or telehealth consultations in the last four weeks irrespective of COVID-19 symptoms; (b) Frontline workers (full time, part time or casual) who were in contact with patients/ clients (with known or unknown status of COVID-19) in the last four weeks, and (c) Community members, who did not consult with GP or allied health service providers in the last four weeks.

\section{Sampling}

All participants fulfilling the inclusion criteria were invited to participate. Sample size was calculated using OpenEpi. Considering 25,464,116 as the population of Australia [10], the prevalence of lifetime mental health issues amongst Australians at 45\% [11], at 95\% confidence intervals and $80 \%$ power, the estimated minimum sample size was 381 . Snowball sampling was used to recruit the study participants.

\section{Data collection}

An online link of the web-based questionnaire was developed using Qualtrics from the Federation University Australia after the ethics approval. The initial eligibility question was related to age and place of residence, which on fulfilling, participants had the opportunity to consent and commence the main study questionnaire. The anonymous questionnaire was introduced and the invitation with the online link and QR code was shared on social media platforms, emails, and text messages. No information which could potentially identify any study participants such as name, residential address, patient identification number were collected. Patients, who visited GP clinics or Allied Healthcare settings, were informed about the study by either receptionists or healthcare professionals. Study details with the survey link and QR code were also displayed at those settings, therefore, any patient willing to participate in the study could access the link by scanning the code or accessing the survey link. However, neither health professionals nor investigators were aware of the patients who participated in the study. Patients had the freedom to complete the questionnaire at their convenience at home or while waiting to visit health professionals, and the online questionnaire did not collect any identifying information from patients.

\section{Study tool}

A structured online survey questionnaire was used to collect data from participants, which was developed based on evidence from studies published previously [12-15]. Data were collected regarding socio-demographics, which included age, gender, state, postcode, living with or without family members, country of birth, and completed level of education. Data regarding profession and current employment condition including the impact of COVID-19 on occupation, self-identification as a frontline health or other essential service worker were also collected. In addition, the collected data included self-reported co-morbidities (cardiac diseases, stroke, hypertension, hyperlipidaemia, diabetes, cancer, chronic respiratory illness, psychological/ mental health problems), behavioural risk factors (smoking and alcohol intake), health service utilization in the last four weeks including type of service providers and access to mental health resources, and history of exposure to COVID-19 including diagnosis and testing. Psychological impact was assessed by the Kessler Psychological Distress Scale (K10) [16], fear was assessed by the Fear of COVID-19 scale (FCV-19S) [17], and coping strategies were assessed by the Brief Resilient Coping Scale (BRCS) [18]. K10 was found to be a valid and reliable tool, with wide applications in research and clinical practice $[16,19$, 20]; FCV-19S was developed more recently in response to the global pandemic of COVID-19, which was validated and tested for reliability in a few recent studies [17, 21, 22]; validity and reliability had also been tested for BRCS in earlier studies [18, 23, 24]. K10 has 10 items and response to each item in the questionnaire was measured using a 5-point Likert scale (none, a little, sometimes, most of the time, all the time). All items were scored, and the total score categorised into low (score 10-15), moderate (score 16-21), high (score 22-29) and very high (score 30-50). FCV-19S has seven items and the response to each item was also measured using a 5-point Likert scale (strongly disagree, somewhat disagree, neither agree nor disagree, somewhat agree, strongly agree), with scores categorised into low (score 7-21) and high (score 22-35). BRCS has four items and responses were collected again using a 5-point Likert scale (does not describe me at all, does not describe me, neutral, describes me, describes me very well), with scores similarly categorised into low (score 4-13), medium (score 14-16) and high (score 17-20) resilient copers. Following ethics approval, the questionnaire was pre-tested and finalised with feedback from the research team.

\section{Data analyses}

The database was downloaded from Qualtrics and analysed using SPSS v.25 and STATA v.12. Descriptive analyses were used to describe the study variables. Mean and standard deviations were calculated for the 
continuous variable (age) and for each scale (K10, FCV$19 \mathrm{~S}$ and BRCS). To conduct inferential analyses, K10 was defined into low (score 10-15) and moderate to very high (score 16-50), and BRCS was also defined into low (score 4-13) and medium to high (score 14-20) resilient copers. Participants, who took $<1 \mathrm{~min}$ to complete the questionnaire, were excluded from the analyses. Initially, the factors associated with psychological distress were identified by comparing low and moderate to very high distress on the K10 scale, factors associated with fear of COVID-19 were identified by comparing low and high fear on the FCV-19S scale, and factors associated with coping were identified by comparing low and medium to high resilient copers on the BRCS scale using Chi-square test. Statistical significance was determined by $p<0.05$. Binary logistic regression was used to assess the strength of association, which yielded odds ratio (OR) and 95\% confidence intervals (CIs). Multivariate analyses were conducted by adjusting the socio-demographic variables (age, gender, living status, country of birth, education, and employment status), and presented as adjusted OR (AOR) with 95\% CI.

\section{Ethics}

Ethics approval was obtained from the Human Research Ethics Committee (HREC) at Federation University Australia (B20-036). Data were collected anonymously and delinked for this online survey. Information on contacting BeyondBlue hotline (free of cost and 24/7 availability) was included in the participant information sheet for any respondent feeling distressed while completing the study questionnaire.

\section{Results}

A total of 587 individuals participated in this study, the majority hailing from Victoria $(88.2 \%)$. Mean age $( \pm$ SD) of the participants was $41.3( \pm 12.5)$ years and $61.8 \%$ were females. Most of them (77.1\%) lived with partners and/or children. More than half of the participants (59.5\%) were born outside of Australia. More than twothirds of the study population $(418,71.5 \%)$ completed at least a Bachelor course. The majority had a source of income (401/561, 71.5\%) during this pandemic, and 76.3\% $(160 / 561)$ were perceived to have moderate to a great deal of distress due to a change of employment status due to COVID-19. Around 59\% of participants also reported financial impact due to COVID-19. More than one-third (42.3\%) identified themselves as frontline or essential service workers, including doctors (11\%), nurses $(9 \%)$ and medical receptionists (3.8\%) (Table 1).

Half of the study participants did not report any comorbidity, and $7.2 \%$ reported having pre-existing psychiatric or mental health issues. The majority of the participants $(86.6 \%)$ were never smokers and more than half
(63\%) did not report drinking alcohol in the last four weeks. However, of those who smoked and drink alcohol, 42.4 and $31.4 \%$ reported increased smoking and alcohol drinking in the last four weeks, respectively. One in five participants $(17.8 \%)$ provided direct or indirect care to the family members or patients with a known or suspected case of COVID-19, and 13.9\% reported selfisolating prior to receiving negative test results or had an overseas travel history. One in ten participants $(11.4 \%)$ visited healthcare providers in person, and $8.9 \%$ had telehealth consultation in the last four weeks for any reason, while $6.9 \%$ had a consultation due to COVID-19 related stress. The latter group who consulted to overcome stress related to COVID-19 used a range of service providers including GPs (31.6\%), mental health support services $(21.1 \%)$, psychologists $(15.8 \%)$ and psychiatrists (7.9\%) (Table 1). Almost a third of the participants experienced high to very high levels of psychological distress (33\%) and high levels of fear of COVID-19 (31.9\%) with almost all of them (97.3\%) being low resilient copers (Tables 2, 3, and 4).

\section{Psychological distress}

Univariate analyses showed that younger participants, participants living without family members, females, those with pre-existing mental health conditions, those that did not identify themselves as frontline workers, those with increased smoking and alcohol drinking in the last four weeks, those self-isolating, those who used health service in general or used health service to overcome COVID-19 related stress in the last four weeks and those with a higher level of fear of COVID-19 were more likely to develop moderate to very high levels of psychological distress compared to their counterparts (Table 5). However, when potential confounders were adjusted, being female (AOR 1.74, 95\% CIs 1.15-2.65, $p=0.009$ ), pre-existing mental health conditions (AOR 3.13, 95\% CIs 1.12-8.75, $p=0.029$ ), high risk behaviours such as increased smoking (AOR 8.66, 95\% CIs 1.0869.1, $p=0.042$ ) and increased alcohol drinking (AOR 2.39, 95\% CIs 1.05-5.47, $p=0.038$ ) in the past four weeks and higher levels of fear of COVID-19 (AOR 2.93, 95\% CIs 1.83-4.67, $p=0.000$ ) were associated with moderate to very high levels of psychological distress. Conversely, being older (60+ years) (AOR 0.29, 95\% CIs $0.11-0.74, p=0.010)$ and being a frontline or essential service worker (AOR 0.64, 95\% CIs 0.42-0.96, $p=0.032$ ) were associated with low levels of psychological distress (Table 5).

\section{Level of fear}

Univariate analyses showed that being middle aged, living with family members, being born overseas, unemployed, those reporting moderate to a great deal of 
Table $\mathbf{2}$ Level of psychological distress among the study participants

Anxiety and Depression Checklist (K10) (last 4 weeks)
About how often did you feel tired out for no good
reason?
None
A little
Sometime
Most of the time
All the time
About how often did you feel nervous?
None
A little
Sometime
Most of the time
All the time
About how often did you feel so nervous that nothing
could calm you down?
None
A little
Sometime
Most of the time
All the time
About how often did you feel hopeless?
Most of the time
All the time
Nometime

About how often did you feel restless or fidgety?

None

A little

Sometime

Most of the time

All the time

\section{$156(28.6)$}

$118(21.6)$

$184(33.7)$

$72(13.2)$

$16(2.9)$

547

$127(23.2)$

$157(28.7)$

$185(33.8)$

$70(12.8)$

8 (1.5)

546

$357(65.4)$

96 (16.4)

$76(13.9)$

$16(2.9)$

$1(0.2)$

547

$258(47.2)$

$151(27.6)$

98 (17.9)

$35(6.4)$

$5(0.9)$

547

$178(32.5)$

$177(32.4)$

$138(25.2)$

$49(9.0)$

$5(0.9)$

About how often did you feel so restless you could not sit still?

None

A little

Sometime

Most of the time

All the time

About how often did you feel so depressed?

None

A little

Sometime

Most of the time
Table 2 Level of psychological distress among the study participants (Continued)

\begin{tabular}{ll}
\hline Anxiety and Depression Checklist (K10) (last $\mathbf{4}$ weeks) & $\begin{array}{l}\text { Total, } \\
\boldsymbol{n}(\%)\end{array}$ \\
\hline All the time & $10(1.8)$
\end{tabular}

About how often did you feel that everything was an $\quad 546$ effort?

$\begin{array}{ll}\text { None } & 179(32.8) \\ \text { A little } & 162(29.7) \\ \text { Sometime } & 119(21.8) \\ \text { Most of the time } & 73(13.4) \\ \text { All the time } & 13(2.4)\end{array}$

About how often did you feel so sad that nothing could 546 cheer you up?

\begin{tabular}{ll} 
None & $297(54.4)$ \\
A little & $149(27.3)$ \\
Sometime & $74(13.6)$ \\
Most of the time & $23(4.2)$ \\
All the time & $3(0.5)$ \\
About how often did you feel worthless? & $\mathbf{5 4 7}$ \\
None & $328(60.0)$ \\
A little & $116(21.2)$ \\
Sometime & $70(12.8)$ \\
Most of the time & $28(5.1)$ \\
All the time & $5(0.9)$ \\
K10 score (total) & $\mathbf{5 4 7}$ \\
Mean ( \pm SD) & $19.6(7.6)$ \\
Range & 10 to 45 \\
Level of psychological distress (K10 categories) & $\mathbf{5 4 7}$ \\
Low (score 10-15) & $205(37.5)$ \\
Moderate (score 16-21) & $160(29.3)$ \\
High (score 22-29) & $111(20.3)$ \\
Very high (score 30-50) & $71(13.0)$ \\
\hline
\end{tabular}

distress due to a change of employment status, those who did not identify themselves as frontline workers, those whose financial situation was impacted, those with current and increased alcohol drinking in the last four weeks, those who used health service to overcome COVID19 related stress in the last four weeks and those with a moderate to very high level of psychological distress were more likely to have higher levels of fear of COVID-19 than other study participants. After adjusting for potential confounders, being female (AOR 1.56, 95\% CIs $1.00-2.45, p=0.052$ ), aged $30-59$ years old (AOR 2.29, 95\% CIs 1.21-4.35, $p=0.011$ ), perceived moderate to a great deal of distress due to a change of employment status (AOR 4.14, 95\% CIs 1.39-12.4, $p=0.011$ ), providing care to known or suspected cases of COVID19 (AOR 3.64, 95\% CIs 1.54-8.58, $p=0.003$ ), increased 
Table 3 Level of fear of COVID-19 among the study participants

\begin{tabular}{l} 
Fear of COVID-19 Scale (FCV-19S) individual items \\
\hline I am most afraid of COVID-19 \\
Strongly disagree \\
Somewhat disagree \\
Neither agree nor disagree \\
Somewhat agree \\
Strongly agree \\
It makes me uncomfortable to think about COVID-19 \\
Strongly disagree \\
Somewhat disagree \\
Neither agree nor disagree \\
Somewhat agree \\
Strongly agree
\end{tabular}

My hands become clammy when I think about COVID19

Strongly disagree
Somewhat disagree
Neither agree nor disagree
Somewhat agree
trongly agree

I am afraid of losing my life because of COVID-19

Strongly disagree

Somewhat disagree

Neither agree nor disagree

Somewhat agree

Strongly agree

When watching news and stories about COVID-19 on social media, I become nervous or anxious

Strongly disagree
Somewhat disagree
Neither agree nor disagree
Somewhat agree
Strongly agree

I cannot sleep because I'm worrying about getting COVID-19

Strongly disagree
Somewhat disagree
Neither agree nor disagree
Somewhat agree
Strongly agree

My heart races or palpitates when I think about getting COVID-19

Strongly disagree

Somewhat disagree

Neither agree nor disagree
549

$172(31.3)$

$76(13.8)$

$125(22.8)$

$123(22.4)$

$53(9.7)$

549

$76(13.8)$

$70(12.8)$

$93(16.9)$

$222(40.4)$

$88(16.0)$

549

$299(54.5)$

$79(14.4)$

95 (17.3)

69 (12.6)

$7(1.3)$

549

$285(51.9)$

86 (15.7)

$93(16.9)$

Table 3 Level of fear of COVID-19 among the study participants (Continued)

\begin{tabular}{ll}
\hline Fear of COVID-19 Scale (FCV-19S) individual items & $\begin{array}{l}\text { Total, } \\
\boldsymbol{n}(\%)\end{array}$ \\
\hline Somewhat agree & $76(13.8)$ \\
Strongly agree & $9(1.6)$ \\
FCV-19S score (total) & $\mathbf{5 4 9}$ \\
Mean ( \pm SD) & $18.4(6.5)$ \\
Range & 7 to 35 \\
Level of fear of COVID-19 (FCV-19S categories) & $\mathbf{5 4 9}$ \\
Low (score 7-21) & $374(68.1)$ \\
High (score 22-35) & $175(31.9)$ \\
\hline
\end{tabular}

alcohol drinking over the last four weeks (AOR 3.64, 95\% CIs 1.54-8.58, $p=0.003$ ), having medium to very high levels of distress based on the K10 scale (AOR 2.90, 95\% CIs 1.82-5.62, $p=0.000$ ), and health service use to overcome COVID-19 related stress in the last four weeks (AOR 3.54, 95\% CIs 1.57-7.99, $p=0.002$ ) were associated with higher levels of fear. On the other hand, being born in Australia (AOR 0.35, 95\% CIs 0.21-0.58, $p=0.000$ ), having a source of income (AOR 0.51, 95\% CIs $0.27-0.95, p=0.033)$, and alcohol drinking in the last four weeks (AOR 0.45, 95\% CIs 0.27-0.74, $p=0.002$ ) were associated with lower level of fear (Table 6).

\section{Coping strategies}

When medium to high resilient copers were compared with low resilient copers based on the BRCS scale, the only significant factor was visiting healthcare providers in person in the last four weeks (OR 4.01, 95\% CIs 1.30$12.4, p=0.016$ ). However, it did not remain statistically significant when sociodemographic variables were adjusted as potential confounders. The study respondents mentioned a varied range of experiences/activities to cope up with the stress from COVID-19. The most emerging themes included engaging in daily exercise, yoga and meditation; watching movies; listening to music and reading books; spending time with kids and partners or focusing on family members; gardening; making phone calls to friends and loved ones; engaging in hobbies one was used to; cleaning home and hand washing; ensuring safe distancing; more prayers and connecting to God; working from home; cooking and eating more; drinking and smoking; not thinking too much about the situation; not watching news/statistics about COVID-19; visiting GPs or psychologist to allay fears and distress and finally, doing nothing special.

\section{Discussion}

This cross-sectional study was one of the earliest carried out among residents of Australia with a view to assess 
Table 4 Coping during COVID-19 pandemic among the study participants

\begin{tabular}{|c|c|}
\hline Brief Resilient Coping Scale (BRCS) individual items & $\begin{array}{l}\text { Total, } \\
n(\%)\end{array}$ \\
\hline I look for creative ways to alter difficult situations & 549 \\
\hline Does not describe me at all & $110(20.0)$ \\
\hline Does not describe me & $255(46.4)$ \\
\hline Neutral & $123(22.4)$ \\
\hline Describes me & $35(6.4)$ \\
\hline Describes me very well & $26(4.7)$ \\
\hline $\begin{array}{l}\text { Regardless of what happens to me, I believe I can } \\
\text { control my reaction to it }\end{array}$ & 549 \\
\hline Does not describe me at all & $133(24.2)$ \\
\hline Does not describe me & $254(46.3)$ \\
\hline Neutral & 109 (19.9) \\
\hline Describes me & $37(6.7)$ \\
\hline Describes me very well & $16(2.9)$ \\
\hline $\begin{array}{l}\text { I believe I can grow in positive ways by dealing with } \\
\text { difficult situations }\end{array}$ & 549 \\
\hline Does not describe me at all & $217(39.5)$ \\
\hline Does not describe me & $254(46.3)$ \\
\hline Neutral & $62(11.3)$ \\
\hline Describes me & $12(2.2)$ \\
\hline Describes me very well & $4(0.7)$ \\
\hline $\begin{array}{l}\text { I actively look for ways to replace the losses I } \\
\text { encounter in life }\end{array}$ & 549 \\
\hline Does not describe me at all & $128(23.3)$ \\
\hline Does not describe me & $243(44.3)$ \\
\hline Neutral & $139(25.3)$ \\
\hline Describes me & $34(6.2)$ \\
\hline Describes me very well & $5(0.9)$ \\
\hline BRCS score (total) & 549 \\
\hline Mean $( \pm \mathrm{SD})$ & $8.4(2.6)$ \\
\hline Range & 4 to 18 \\
\hline Level of coping (BRCS categories) & 549 \\
\hline Low resilient copers (score 4-13) & $534(97.3)$ \\
\hline Medium resilient copers (score 14-16) & $12(2.2)$ \\
\hline High resilient copers (score 17-20) & $3(0.5)$ \\
\hline
\end{tabular}

the extent of and identify factors associated with psychological distress, level of fear and coping strategies during the COVID-19 pandemic. Being female and increased alcohol drinking in the past four weeks were associated with higher psychological distress and higher levels of fear of COVID-19 in this study. In addition, higher psychological distress was associated with pre-existing mental health conditions, increased smoking in the last four weeks and higher levels of fear of COVID-19 while lower psychological distress was associated with being older
(60+ years) and being a frontline or essential service worker. A higher level of fear was associated with being 30-59 years old, perceived distress due to change of employment status, providing care to known or suspected case of COVID-19 and having higher level of psychological distress. On the other hand, a lower level of fear was associated with being born in Australia, having a source of income and alcohol drinking in the last four weeks. Visiting healthcare providers in person in the last four weeks was also found to be associated with coping during the COVID-19 pandemic.

Previous research has revealed a profound and wide range of psychosocial impacts on people at the individual and community level during outbreaks of infection [25]. However, it will be somewhat early to predict similar results emanating during the peak of the COVID-19 epidemic, with the uncertainty surrounding an outbreak of such unparalleled magnitude. A recent study carried out in 194 cities in China showed 53.8\% respondents rating psychological impact as moderate to severe [14]. This finding coincides with our study as it raised almost similar levels (moderate to very high level) of psychological distress (62.6\%) among the study participants. A study from the UK showed that the prevalence of poor mental health was 37\% amongst participants who were in isolation or maintaining social distancing, where poor mental health was defined as having moderate to severe depressive symptoms and anxiety [26]. Similarly, the Australian Bureau of Statistics had been collecting COVID-19 impact survey data fortnightly involving a representative sample of over 1000 adults across Australia, and findings indicated twice as many adults experiencing anxiety, nervousness and restlessness compared to pre-COVID surveillance data [27].

Evidence suggests that pre-existing anxiety disorders, existing health anxiety (those who worry excessively about having or contracting illnesses), and other mental health disorders (e.g., depression and post-traumatic stress) are at risk of experiencing higher anxiety levels during the COVID-19 outbreak [28]. Similarly, our study showed a significantly higher level of psychological distress among participants having pre-existing comorbidities such as psychiatric or mental health issues. Individuals who were self-isolating prior to receiving negative results for COVID-19 also showed heightened psychological stress and this was corroborated by another study, which identified anxiousness and feelings of guilt by the quarantined persons [14]. In addition, a sense of stigma from other family members or friends might have contributed to such high levels of distress [29]. Findings related to self-identification as a frontline or essential service worker exhibiting a lower level of stress in the present study was somewhat incongruous with other initial studies, which showed a significant 
Table 5 Factors associated with high psychological distress among the study population (based on K10 score)

\begin{tabular}{|c|c|c|c|c|c|c|c|c|}
\hline \multirow[t]{2}{*}{ Characteristics } & \multirow{2}{*}{$\begin{array}{l}\text { Moderate to Very High } \\
\text { (score } 16-50), n(\%)\end{array}$} & \multirow{2}{*}{$\begin{array}{l}\text { Low } \\
\text { (score 10-15), } n(\%)\end{array}$} & \multicolumn{3}{|c|}{ Unadjusted analyses } & \multicolumn{3}{|c|}{ Adjusted analyses } \\
\hline & & & $p$ & OR & $95 \% \mathrm{Cls}$ & $p$ & AOR & $95 \% \mathrm{Cls}$ \\
\hline Total study participants & 341 & 205 & & & & & & \\
\hline Age groups & 313 & 187 & & & & & & \\
\hline 18-29 years & $72(23.0)$ & $25(13.4)$ & & 1 & & & 1 & \\
\hline $30-59$ years & 224 (71.6) & $139(74.3)$ & 0.023 & 0.56 & $0.34-0.92$ & 0.358 & 0.75 & $0.41-1.37$ \\
\hline $60+$ years & $17(5.4)$ & $23(12.3)$ & 0.001 & 0.26 & $0.12-0.56$ & 0.010 & 0.29 & $0.11-0.74$ \\
\hline Gender & 341 & 205 & & & & & & \\
\hline Male & $106(31.1)$ & $98(47.8)$ & & 1 & & & 1 & \\
\hline Female & $235(68.9)$ & $107(52.2)$ & 0.000 & 2.03 & $1.42-2.90$ & 0.009 & 1.74 & $1.15-2.65$ \\
\hline Living status & 339 & 205 & & & & & & \\
\hline $\begin{array}{l}\text { Live without family members (on your own/ } \\
\text { shared house/others) }\end{array}$ & $87(25.7)$ & $36(17.6)$ & & 1 & & & 1 & \\
\hline $\begin{array}{l}\text { Live with family members (partner and/or } \\
\text { children) }\end{array}$ & $252(74.3)$ & $169(82.4)$ & 0.029 & 0.62 & $0.40-0.95$ & 0.210 & 0.71 & $0.41-1.22$ \\
\hline Born in Australia & 342 & 205 & & & & & & \\
\hline No & $200(58.5)$ & $126(61.5)$ & & 1 & & & 1 & \\
\hline Yes & $142(41.5)$ & 79 (38.5) & 0.491 & 1.13 & $0.79-1.61$ & 0.623 & 1.12 & $0.70-1.80$ \\
\hline Completed level of education & 342 & 205 & & & & & & \\
\hline Grade 1-12 & $43(12.6)$ & $26(12.7)$ & & 1 & & & 1 & \\
\hline Trade/Certificate/Diploma & $62(18.1)$ & $22(10.7)$ & 0.129 & 1.7 & $0.86-3.39$ & 0.106 & 1.89 & $0.87-4.09$ \\
\hline Bachelor and above & $237(69.3)$ & $157(76.6)$ & 0.734 & 0.91 & $0.54-1.55$ & 0.974 & 1.01 & $0.52-1.95$ \\
\hline Current employment condition & 326 & 195 & & & & & & \\
\hline Unemployed/Home duties & $44(13.5)$ & $19(9.7)$ & & 1 & & & 1 & \\
\hline $\begin{array}{l}\text { Jobs affected by COVID-19 (lost job/working } \\
\text { hours reduced/afraid of job loss) }\end{array}$ & $59(18.1)$ & $22(11.3)$ & 0.693 & 1.16 & $0.56-2.40$ & 0.948 & 1.02 & $0.46-2.32$ \\
\hline $\begin{array}{l}\text { Have an income source (employed/ } \\
\text { Government benefits) }\end{array}$ & $223(68.4)$ & $154(79.0)$ & 0.110 & 0.63 & $0.35-1.11$ & 0.113 & 0.59 & $0.30-1.14$ \\
\hline $\begin{array}{l}\text { Perceived distress due to change of } \\
\text { employment status }\end{array}$ & 118 & 33 & & & & & & \\
\hline A little to none & $27(22.9)$ & $10(30.3)$ & & 1 & & & 1 & \\
\hline Moderate to a great deal & $91(77.1)$ & $23(69.7)$ & 0.383 & 1.47 & $0.62-3.45$ & 0.399 & 1.58 & $0.55-4.54$ \\
\hline $\begin{array}{l}\text { Self-identification as a frontline or essential } \\
\text { service worker }\end{array}$ & 342 & 205 & & & & & & \\
\hline No & $213(62.3)$ & $101(49.3)$ & & 1 & & & 1 & \\
\hline Yes & $129(37.7)$ & $104(50.7)$ & 0.003 & 0.59 & $0.41-0.83$ & 0.032 & 0.64 & $0.42-0.96$ \\
\hline COVID-19 impacted financial situation & 341 & 205 & & & & & & \\
\hline No & $137(40.2)$ & $91(44.4)$ & & 1 & & & 1 & \\
\hline Yes & $204(59.8)$ & $114(55.6)$ & 0.334 & 1.19 & $0.84-1.69$ & 0.534 & 1.14 & $0.76-1.72$ \\
\hline Co-morbidities & 342 & 205 & & & & & & \\
\hline No & $169(49.4)$ & $104(50.7)$ & & 1 & & & 1 & \\
\hline Psychiatric/Mental health issues & $36(10.5)$ & $5(2.4)$ & 0.003 & 4.43 & $1.69-11.7$ & 0.029 & 3.13 & $1.12-8.75$ \\
\hline Other co-morbidities* & $137(40.1)$ & $96(46.8)$ & 0.476 & 0.88 & $0.61-1.26$ & 0.613 & 1.11 & $0.73-1.69$ \\
\hline Smoking & 267 & 158 & & & & & & \\
\hline Never smoker & $226(84.6)$ & $144(91.1)$ & & 1 & & & 1 & \\
\hline Ever smoker (Daily/Non-daily/Ex) & $41(15.4)$ & $14(8 / 9)$ & 0.054 & 1.87 & $0.98-3.55$ & 0.054 & 2.03 & $0.99-4.17$ \\
\hline Increased smoking over the last 4 weeks & 41 & 14 & & & & & & \\
\hline
\end{tabular}


Table 5 Factors associated with high psychological distress among the study population (based on K10 score) (Continued)

\begin{tabular}{|c|c|c|c|c|c|c|c|c|}
\hline \multirow[t]{2}{*}{ Characteristics } & \multirow{2}{*}{$\begin{array}{l}\text { Moderate to Very High } \\
\text { (score 16-50), } n(\%)\end{array}$} & \multirow{2}{*}{$\begin{array}{l}\text { Low } \\
\text { (score 10-15), } n(\%)\end{array}$} & \multicolumn{3}{|c|}{ Unadjusted analyses } & \multicolumn{3}{|c|}{ Adjusted analyses } \\
\hline & & & $p$ & OR & $95 \% \mathrm{Cls}$ & $p$ & AOR & $95 \% \mathrm{Cls}$ \\
\hline No & $22(53.7)$ & $12(85.7)$ & & 1 & & & 1 & \\
\hline Yes & $19(46.3)$ & $2(14.3)$ & 0.046 & 5.18 & $1.03-26.1$ & 0.042 & 8.66 & $1.08-69.1$ \\
\hline Current alcohol drinking (last 4 weeks) & 341 & 205 & & & & & & \\
\hline No & $206(60.4)$ & $138(67.3)$ & & 1 & & & 1 & \\
\hline Yes & $135(39.6)$ & $67(32.7)$ & 0.106 & 1.35 & $0.94-1.94$ & 0.196 & 1.35 & $0.85-2.15$ \\
\hline $\begin{array}{l}\text { Increased alcohol drinking over the last } 4 \\
\text { weeks }\end{array}$ & 134 & 65 & & & & & & \\
\hline No & $84(62.7)$ & $54(83.1)$ & & 1 & & & 1 & \\
\hline Yes & $50(37.3)$ & $11(16.9)$ & 0.004 & 2.92 & $1.40-6.11$ & 0.038 & 2.39 & $1.05-5.47$ \\
\hline $\begin{array}{l}\text { Provided care to a family member/patient } \\
\text { with known/suspected case of COVID-19 }\end{array}$ & 321 & 195 & & & & & & \\
\hline No & $281(82.2)$ & $170(82.9)$ & & 1 & & & 1 & \\
\hline Yes & $61(17.8)$ & $35(17.1)$ & 0.820 & 1.05 & $0.67-1.67$ & 0.841 & 1.05 & $0.63-1.76$ \\
\hline Experience related to COVID-19 pandemic & 342 & 205 & & & & & & \\
\hline $\begin{array}{l}\text { I have been self-isolating prior to receiving } \\
\text { negative result for COVID-19 }\end{array}$ & $52(15.2)$ & $19(9.3)$ & 0.048 & 1.76 & $1.01-3.06$ & 0.082 & 1.75 & $0.93-3.30$ \\
\hline Healthcare service use in the last 4 weeks & 342 & 205 & & & & & & \\
\hline No & $255(74.6)$ & $178(86.8)$ & & 1 & & & 1 & \\
\hline Visited healthcare providers in person & $47(13.7)$ & $17(8.3)$ & 0.028 & 1.93 & $1.07-3.47$ & 0.983 & 1.01 & $0.30-3.41$ \\
\hline $\begin{array}{l}\text { Telehealth consultation with healthcare } \\
\text { providers/National helpline }\end{array}$ & $40(11.7)$ & $10(4.9)$ & 0.005 & 2.79 & $1.36-5.73$ & 0.408 & 0.46 & $0.07-2.93$ \\
\hline $\begin{array}{l}\text { Level of fear of COVID-19 (FCV-19S } \\
\text { categories) }\end{array}$ & 342 & 205 & & & & & & \\
\hline Low (score 7-21) & $207(60.5)$ & $166(81.0)$ & & 1 & & & 1 & \\
\hline High (score 22-35) & $135(39.5)$ & $39(19.0)$ & 0.000 & 2.78 & 1.84-4.19 & 0.000 & 2.93 & $1.83-4.67$ \\
\hline Level of coping (BRCS categories) & 342 & 205 & & & & & & \\
\hline Low resilient copers (score 4-13) & $333(97.4)$ & $200(97.6)$ & & 1 & & & 1 & \\
\hline Medium to high resilient copers (score 14-20) & $9(2.6)$ & $5(2.4)$ & 0.89 & 1.08 & $0.36-3.27$ & 0.741 & 1.22 & $0.38-3.87$ \\
\hline $\begin{array}{l}\text { Healthcare service use to overcome COVID- } \\
19 \text { related stress in the last } 4 \text { weeks }\end{array}$ & 342 & 205 & & & & & & \\
\hline No & $306(89.5)$ & $203(99.0)$ & & 1 & & & 1 & \\
\hline Yes & $36(10.5)$ & $2(6.9)$ & 0.001 & 11.9 & $2.84-50.1$ & 0.004 & 20.2 & $2.64-154$ \\
\hline
\end{tabular}

Adjusted for: age, gender, living status, born in Australia, education and employment

${ }^{*}$ Cardiac diseases/Stroke/Hypertension/Hyperlipidaemia/Diabetes/Cancer/Chronic respiratory illness

mental health burden on frontline healthcare workers during pandemics [30]. A recent systematic review of 59 studies with 54,707 participants showed that one or two of every five healthcare professionals reported anxiety, depression, distress and/or sleep problems during the current COVID-19 pandemic, which were primarily associated with increased workload [31]. Due to the small number of participants, our study could not conduct subgroup analyses focusing on frontline healthcare providers and our findings of lower levels of distress among these groups could be due to the prolonged exposure of the pandemic period, being accustomed with service provision as frontline workers and/or availability of personal protective equipment.

The COVID-19 pandemic also led to maladaptive behaviours, including increased smoking and alcohol intake due to stress and social isolation [4]. Previous studies also found that patients with a history of smoking are at higher risk of severe COVID disease, and those admitted to intensive care, may require ventilation [32]. Our study has found significant association between increased smoking as well as alcohol drinking and higher psychological distress. Evidence from previous studies indicated community-wide disasters being 
Table 6 Factors associated with levels of fear of COVID-19 among the study population (based on FCV-19S score)

\begin{tabular}{|c|c|c|c|c|c|c|c|c|}
\hline \multirow[t]{2}{*}{ Characteristics } & \multirow{2}{*}{$\begin{array}{l}\text { High } \\
\text { (score 22-35), } n(\%)\end{array}$} & \multirow{2}{*}{$\begin{array}{l}\text { Low } \\
\text { (score 7-21), } n(\%)\end{array}$} & \multicolumn{3}{|c|}{ Unadjusted analyses } & \multicolumn{3}{|c|}{ Adjusted analyses } \\
\hline & & & $\bar{p}$ & OR & $95 \% \mathrm{Cls}$ & $\bar{p}$ & AOR & $95 \% \mathrm{Cls}$ \\
\hline Total study participants & 175 & 374 & & & & & & \\
\hline Age groups & 162 & 339 & & & & & & \\
\hline $18-29$ years & $22(13.6)$ & $75(22.1)$ & & 1 & & & 1 & \\
\hline 30-59 years & $131(80.9)$ & $233(68.7)$ & 0.014 & 1.92 & $1.14-3.23$ & 0.011 & 2.29 & $1.21-4.35$ \\
\hline $60+$ years & $9(5.6)$ & $31(9.1)$ & 0.982 & 0.99 & $0.41-2.39$ & 0.551 & 1.37 & $0.49-3.84$ \\
\hline Gender & 174 & 374 & & & & & & \\
\hline Male & $61(35.1)$ & $145(38.8)$ & & 1 & & & 1 & \\
\hline Female & $113(64.9)$ & $229(61.2)$ & 0.404 & 1.17 & $0.81-1.71$ & 0.052 & 1.56 & $1.00-2.45$ \\
\hline Living status & 174 & 371 & & & & & & \\
\hline $\begin{array}{l}\text { Live without family members (on your own/shared } \\
\text { house/others) }\end{array}$ & $29(16.7)$ & 95 (25.6) & & 1 & & & 1 & \\
\hline Live with family members (partner and/or children) & $145(83.3)$ & $276(74.4)$ & 0.020 & 1.72 & $1.08-2.73$ & 0.502 & 1.22 & $0.69-2.16$ \\
\hline Born in Australia & 175 & 374 & & & & & & \\
\hline No & $127(72.6)$ & $200(53.5)$ & & 1 & & & 1 & \\
\hline Yes & $48(27.4)$ & $174(46.5)$ & 0.000 & 0.43 & $0.29-0.64$ & 0.000 & 0.35 & $0.21-0.58$ \\
\hline Completed level of education & 175 & 373 & & & & & & \\
\hline Grade 1-12 & 19 (10.9) & $50(13.4)$ & & 1 & & & 1 & \\
\hline Trade/Certificate/Diploma & $26(14.9)$ & $59(15.8)$ & 0.679 & 1.16 & $0.58-2.34$ & 0.414 & 0.72 & $0.32-1.59$ \\
\hline Bachelor and above & $130(74.3)$ & $264(70.8)$ & 0.372 & 1.30 & $0.74-2.29$ & 0.129 & 0.58 & $0.29-1.17$ \\
\hline Current employment condition & 169 & 354 & & & & & & \\
\hline Unemployed/Home duties & $28(16.6)$ & $35(9.9)$ & & 1 & & & 1 & \\
\hline $\begin{array}{l}\text { Jobs affected by COVID-19 (lost job/working hours } \\
\text { reduced/afraid of job loss) }\end{array}$ & $40(23.7)$ & $42(11.9)$ & 0.604 & 1.19 & $0.62-2.30$ & 0.517 & 1.28 & $0.6-2.69$ \\
\hline $\begin{array}{l}\text { Have an income source (employed/Government } \\
\text { benefits) }\end{array}$ & $101(59.8)$ & $277(78.2)$ & 0.005 & 0.46 & $0.26-0.79$ & 0.033 & 0.51 & $0.27-0.95$ \\
\hline $\begin{array}{l}\text { Perceived distress due to change of employment } \\
\text { status }\end{array}$ & 60 & 92 & & & & & & \\
\hline A little to none & $6(10.0)$ & $31(33.7)$ & & 1 & & & 1 & \\
\hline Moderate to a great deal & $54(90.0)$ & $61(66.3)$ & 0.002 & 4.57 & $1.77-11.8$ & 0.011 & 4.14 & $1.39-12.4$ \\
\hline $\begin{array}{l}\text { Self-identification as a frontline or essential } \\
\text { service worker }\end{array}$ & 175 & 374 & & & & & & \\
\hline No & $113(64.6)$ & $202(54.0)$ & & 1 & & & 1 & \\
\hline Yes & $62(35.4)$ & $172(46.0)$ & 0.020 & 0.64 & $0.44-0.93$ & 0.065 & 0.66 & $0.43-1.03$ \\
\hline COVID-19 impacted financial situation & 175 & 372 & & & & & & \\
\hline No & $60(34.3)$ & $169(45.4)$ & & 1 & & & 1 & \\
\hline Yes & $115(65.7)$ & $203(54.6)$ & 0.014 & 1.60 & $1.10-2.32$ & 0.297 & 1.26 & $0.82-1.95$ \\
\hline Co-morbidities & 175 & 374 & & & & & & \\
\hline No & $91(52.0)$ & $184(49.2)$ & & 1 & & & 1 & \\
\hline Psychiatric/Mental health issues & $12(6.9)$ & $29(7.8)$ & 0.626 & 0.84 & $0.41-1.72$ & 0.952 & 1.02 & $0.49-2.12$ \\
\hline Other co-morbidities* & $72(41.1)$ & $161(43.0)$ & 0.598 & 0.90 & $0.62-1.32$ & 0.698 & 1.09 & $0.69-1.72$ \\
\hline Smoking & 138 & 288 & & & & & & \\
\hline Never smoker & $117(84.8)$ & $254(88.2)$ & & 1 & & & 1 & \\
\hline Ever smoker (Daily/Non-daily/Ex) & $21(15.2)$ & $34(11.8)$ & 0.326 & 1.34 & $0.75-2.41$ & 0.430 & 1.31 & $0.67-2.59$ \\
\hline Increased smoking over the last 4 weeks & 21 & 34 & & & & & & \\
\hline No & $12(57.1)$ & $22(64.7)$ & & 1 & & & 1 & \\
\hline
\end{tabular}


Table 6 Factors associated with levels of fear of COVID-19 among the study population (based on FCV-19S score) (Continued)

\begin{tabular}{|c|c|c|c|c|c|c|c|c|}
\hline \multirow[t]{2}{*}{ Characteristics } & \multirow{2}{*}{$\begin{array}{l}\text { High } \\
\text { (score 22-35), } n(\%)\end{array}$} & \multirow{2}{*}{$\begin{array}{l}\text { Low } \\
\text { (score 7-21), } n(\%)\end{array}$} & \multicolumn{3}{|c|}{ Unadjusted analyses } & \multicolumn{3}{|c|}{ Adjusted analyses } \\
\hline & & & $p$ & OR & $95 \% \mathrm{Cls}$ & $p$ & AOR & $95 \% \mathrm{Cls}$ \\
\hline Yes & $9(42.9)$ & $12(35.3)$ & 0.575 & 1.38 & $0.45-4.19$ & 0.902 & 1.09 & $0.29-4.14$ \\
\hline Current alcohol drinking (last 4 weeks) & 174 & 374 & & & & & & \\
\hline No & $131(75.3)$ & $215(57.5)$ & & 1 & & & 1 & \\
\hline Yes & $43(24.7)$ & $159(42.5)$ & 0.000 & 0.44 & $0.30-0.66$ & 0.002 & 0.45 & $0.27-0.74$ \\
\hline Increased alcohol drinking over the last 4 weeks & 41 & 158 & & & & & & \\
\hline No & $20(48.8)$ & $118(74.7)$ & & 1 & & & 1 & \\
\hline Yes & $21(51.2)$ & $40(25.3)$ & 0.002 & 3.10 & $1.52-6.30$ & 0.003 & 3.64 & $1.54-8.58$ \\
\hline $\begin{array}{l}\text { Provided care to a family member/patient with } \\
\text { known/suspected case of COVID-19 }\end{array}$ & 175 & 374 & & & & & & \\
\hline No & $144(82.3)$ & $308(82.4)$ & & 1 & & & 1 & \\
\hline Yes & $31(17.7)$ & $66(17.6)$ & 0.985 & 1.01 & $0.63-1.61$ & 0.929 & 0.98 & $0.57-1.67$ \\
\hline Healthcare service use in the last 4 weeks & 175 & 374 & & & & & & \\
\hline No & $133(76.0)$ & $302(80.7)$ & & 1 & & & 1 & \\
\hline Visited healthcare providers in person & $21(12.0)$ & $43(11.5)$ & 0.718 & 1.11 & $0.63-1.94$ & 0.410 & 1.52 & $0.56-4.15$ \\
\hline $\begin{array}{l}\text { Telehealth consultation with healthcare providers/ } \\
\text { National helpline }\end{array}$ & $21(12.0)$ & $29(7.8)$ & 0.103 & 1.64 & $0.90-2.99$ & 0.163 & 3.21 & $0.62-16.5$ \\
\hline Level of psychological distress (K10 categories) & 174 & 373 & & & & & & \\
\hline Low (score 10-15) & $39(22.4)$ & $166(44.5)$ & & 1 & & & 1 & \\
\hline Medium to Very high (score $16-50$ ) & $135(77.6)$ & $207(55.5)$ & 0.000 & 2.78 & $1.84-4.19$ & 0.000 & 2.90 & $1.82-4.62$ \\
\hline Level of coping (BRCS categories) & 175 & 374 & & & & & & \\
\hline Low resilient copers (score 4-13) & $170(97.1)$ & $364(97.3)$ & & 1 & & & 1 & \\
\hline Medium to high resilient copers (score 14-20) & $5(2.9)$ & $10(2.7)$ & 0.902 & 1.07 & $0.36-3.18$ & 0.953 & 0.96 & $0.28-3.32$ \\
\hline $\begin{array}{l}\text { Healthcare service use to overcome COVID-19 re- } \\
\text { lated stress in the last } 4 \text { weeks }\end{array}$ & 175 & 374 & & & & & & \\
\hline No & $157(89.7)$ & $354(94.7)$ & & 1 & & & 1 & \\
\hline Yes & $18(10.3)$ & $20(5.3)$ & 0.037 & 2.03 & $1.04-3.94$ & 0.002 & 3.54 & $1.57-7.99$ \\
\hline
\end{tabular}

Adjusted for: age, gender, living status, born in Australia, education and employment

${ }^{*}$ Cardiac diseases/Stroke/Hypertension/Hyperlipidaemia/Diabetes/Cancer/Chronic respiratory illness

associated with a number of behavioural health outcomes including increased mental health concerns and escalations in the use of alcohol [33, 34].

Social distancing, stay at home orders and quarantine measures may lead to boredom, uncertainty and disruption to routines and distress resulting in elevated psychological distress as found in our present study. Increased alcohol consumption might also be explained as a coping mechanism for the perceived distress as many self-medication hypotheses posit use of substances like alcohol for relieving distress [35]. Our study results are also consistent with the findings from a literature review which documented an increase in alcohol consumption for some populations, particularly men, because of added mental stress due to uncertainty about the future due to COVID-19, and economic and employment concerns experienced as a result of the pandemic [36]. The same can be stated regarding increased smoking, as most nicotine consumers reported using nicotine products as their main stress and anxiety coping mechanism. A multi-country study conducted in Italy, India, South Africa, the United Kingdom and the United States have revealed that during the COVID-19 pandemic, cigarette smokers have been buying more cigarettes than usual triggered by the fear that stores might run out of stock or be closed during lock down [37]. Another study from the USA reported that one-third of the participants increased their tobacco use during the COVID-19 pandemic and subsequent 'stay-at-home' orders; that negative behaviour was associated with sociodemographic variables and depression [38].

Our study showed females had higher distress and fear of COVID-19, which was consistent with studies from China [39], Italy [40] and the USA [41] suggesting that female gender was a consistent predictor for psychological distress. A host of reasons can be postulated for this as females disproportionately share the larger percentage of caregiving roles, in both formal and informal 
sectors. They also serve as the primary caregivers more frequently, within a household, which may further accentuate their anxiety and stress in a pandemic situation [42]. The abovementioned Chinese studies also showed that young adults (aged 18-30 years) exhibited the highest level of psychological distress, which was consistent with our study findings. Such distress could be correlated with an increased use of social media, as young participants may watch and listen to much more negative news, which would then intensify their feelings of anxiety and depression in times of crisis.

Higher levels of fear amongst middle-aged participants in our study were more likely due to being part of the workforce with possible financial uncertainly in the event of future job loss. This could also be a possible explanation of accentuation of psychological distress, and therefore, participants utilised more healthcare services (by physical visits or through telehealth) to overcome the COVID-19 related stress during the study period. Like previous studies, our study also found that fear of COVID-19 was a prominent risk factor for the onset and maintenance of increased alcohol consumption [36]. This explains why participants used alcohol as part of their neuro-adaptations and coping response to the stress (induced by fear) because of the pandemic and social isolation [43].

The results of our study further illuminated additional aspects of the factors relating to fear of COVID-19. Level of education did not have any impact on the fear of COVID-19. Similarly, participants had no association between fear and having any existing comorbidities or increased healthcare utilisation. No association was also found between fear and providing care to family or patients with known or suspected COVID-19. There could be multiple possible explanations for this finding. First, a third of the participants, being frontline essential workers, somehow accepted the situation and their role as caregivers or service providers to the family and population they served, respectively. Second, the pandemic was not regarded as severe in intensity in Australia during the study period (June 2020). Third, it could have been that participants were less aware of the severity of the virus; and finally, trust in the initiatives taken by the Australian Government, including stage 3 restrictions with banning of non-essential travel between and within the states and social isolation to prevent the exponential spread of the virus. Participants born in Australia also experienced less fear compared to those not born in Australia, which might be related to better knowledge about the health system, support networks and stronger coping by the Australia born residents. Another study from Australia reported that self-perceived probability of losing jobs was greater amongst people who were born overseas in a non-English speaking country compared to those who were born in Australia, which could also explain the higher psychological distress in non-Australian born residents in our study [44]. However, it was beyond the scope of this study to examine all the relevant factors. Our study demonstrated that frontline or essential workers were less fearful than their counterparts, which could be explained by the availability of increased testing and personal protective equipment for the health care and frontline workers.

More respondents in our study completed bachelor and above qualifications, possibly due to higher number of front line or essential service workers taking part in this survey, who would presumably had higher education than others. According to the International Labour Market (ILO), almost 25 million jobs could be lost worldwide due to COVID-19 [45]. However, pervasive job loss was not evident among our study population as one-third of them were working as frontline or essential service workers who would not necessarily lose jobs during such a crisis, and other participants might have benefitted from the employment support initiative by the Australian Government like jobseeker or jobkeeper payment $[46,47]$. Accordingly, employment status of our study participants might not reflect the true job loss situation in Australia due to the ongoing pandemic of COVID-19.

\section{Limitations}

The survey responses in this study were predominantly from Victoria although the survey link was shared across all the states in Australia through various social media platforms and emails. This could be explained by the researchers' use of snowball sampling technique as community acquaintances and their accessibility to GP clinics/ allied health service facilities in Victoria than in the other Australian states. Therefore, findings of this study might be more generalisable to the State of Victoria rather than across Australia, and it was also likely that distressed individuals had responded to our survey resulting in selection bias. A significant number of participants in the study were not born in Australia, which is a reflection of the country's multiculturalism. According to the Australian Bureau of Statistics, almost $30 \%$ of Australians were born overseas, increasing the cultural diversity of Australia's population [48]. More females than males participated in the survey, which could be due to more frequent visits to healthcare providers by females than males [49], and increased number of female workforce being employed in the frontline healthcare or essential service facilities/outlets [50]. Findings of our study were limited to people who could access online platforms to participate; hence, generalizability was limited to internet-literate people. Considering the restrictions of movement and social distancing, an online 
survey was the only viable option during the pandemic to address our research objectives. However, the strength of the study was the achievement of the target sample size within the crisis period; hence the study had significant power to test the hypotheses.

Social distancing and self-isolation due to the current COVID-19 pandemic were likely to be stressful for people. Therefore, it was also important to understand responses from our study participants regarding their coping strategies, considering some groups could be more vulnerable than others to the psychosocial effects of the pandemic. Findings of our study were supported by prior research outlining coping activities like social connection with families and friends, limiting exposure to pandemic-related news, maintaining adequate sleep, nutrition, exercise, and practicing meditation (mindfulness) [51].

\section{Conclusions}

This study identified individuals who were at higher risk of distress and fear during the COVID-19 pandemic situation, specifically in the State of Victoria, Australia. People with higher psychological distress increased their use of smoking and alcohol during the pandemic period, which warrants targeting behavioural interventions specifically for those groups and incorporating information on available support services to quit smoking and reduce alcohol use in health awareness campaigns during such pandemic periods of uncertainty.

People with pre-existing mental health conditions were also more likely to experience higher psychological distress, which could worsen their overall wellbeing. An automated alert from primary healthcare providers to those vulnerable individuals for a follow-up visit would be invaluable in managing their distress. In addition, our study indicated that females were more vulnerable to psychological distress, and as such socio-cultural contexts rather than biomedical contexts influenced their mental health, which should be recognised and supported accordingly. Specific interventions to support the mental wellbeing of higher risk individuals as identified in this study should be considered in addition to existing resources within primary healthcare settings. Innovative technologies such as interactive mobile apps to support mental wellbeing can be developed and tested for effectiveness in future experimental studies.

\section{Acknowledgements}

We would like to acknowledge the support from all the healthcare professionals who assisted in collecting data from patients in general practice settings, specifically Dr. Munirul Islam, Dr. Rumana Reza and Dr. Mohammad Mostofa. In addition, we would like to acknowledge the support of Bangladesh Medical Society of Victoria (BMSV) and specifically the kind participation of all the study participants, who donated their valuable time within the crisis period of coronavirus pandemic in Australia.

\section{Authors' contributions}

MAR conceived the study, performed the statistical analyses and drafted the manuscript. NH, SMA, MS, SMSI, BB, AS, NBN, FS and WC contributed for planning, data collection, preparation and critical review of the manuscript. All authors read and approved the final manuscript.

\section{Funding}

The authors confirm there has been no financial support for this work.

\section{Availability of data and materials}

The datasets used and/or analysed during the current study are available from the corresponding author on reasonable request.

\section{Ethics approval and consent to participate}

This study was approved by Human Research Ethics Committee at Federation University Australia (B20-036). Each study participant read the consent form along with plain language summary and ticked their consent in the online form prior to accessing the study questionnaire.

\section{Consent for publication}

Data were collected anonymously, therefore, no identifying information were collected from the study participants.

\section{Competing interests}

The authors confirm that there are no known conflicts of interest associated with this publication.

\section{Author details}

${ }^{1}$ School of Health, Federation University Australia, 100 Clyde Road, Berwick, Victoria 3806, Australia. ${ }^{2}$ Australian Institute of Primary Care and Ageing, La Trobe University, Plenty Road and Kingsbury Drive, Melbourne, Victoria 3086, Australia. ${ }^{3}$ Bangladesh Medical Society of Victoria (BMSV), Melbourne, VIC 3000, Australia. ${ }^{4}$ Emerald Medical Centre, 1 Murphys Way, Emerald, Victoria 3782, Australia. ${ }^{5}$ School of Public Health and Preventive Medicine, Monash University, 553 St Kilda Road, Melbourne, Victoria 3004, Australia. IInstitute for Physical Activity and Nutrition, Deakin University, 221 Burwood Highway, Burwood, Victoria 3125, Australia. ${ }^{7}$ Station Street Clinic, 34 Station Street, Pakenham, Burwood, Victoria 3810, Australia. ${ }^{8}$ Bangladesh Institute of Family Medicine and Research, University of Science \& Technology Chittagong, Zakir Hossain Road, Foy's Lake, Khulshi, Chittagong 4202, Bangladesh. ${ }^{9}$ Greenvale Medical Centre, 1/11 Greenvale Drive, Greenvale, Burwood, Victoria 3059, Australia. ${ }^{10}$ Telstra Health, 222 Lonsdale Street, Melbourne, Victoria 3000, Australia.

Received: 11 August 2020 Accepted: 29 September 2020

Published online: 08 October 2020

\section{References}

1. Worldometer. COVID-19 Coronavirus Pandemic [Available from: https:// www.worldometers.info/coronavirus.

2. Australian Government Department of Health. Coronavirus (COVID-19) current situation and case numbers [Available from: https://www.health.gov. au/news/health-alerts/novel-coronavirus-2019-ncov-health-alert/coronaviruscovid-19-current-situation-and-case-numbers.

3. Van Rheenen TE, Meyer D, Neill E, Phillipou A, Tan EJ, Toh WL, et al. Mental health status of individuals with a mood-disorder during the COVID-19 pandemic in Australia: initial results from the COLLATE project. J Affect Disord. 2020;275:69-77.

4. Stanton R, To QG, Khalesi S, Williams SL, Alley SJ, Thwaite TL, et al. Depression, Anxiety and Stress during COVID-19: Associations with Changes in Physical Activity, Sleep, Tobacco and Alcohol Use in Australian Adults. Int J Environ Res Public Health. 2020;17(11)

5. Roy Morgan. Roy Morgan Unemployment Profile Melbourne, Australia. 2020 [Available from: http://www.roymorgan.com/morganpoll/unemployment/ estimates-detailed.

6. Ministers Department of Health: Australian Government. COVID-19: Whole of population telehealth for patients, general practice, primary care and other medical services 2020 [Available from: https:/www.health.gov.au/ ministers/the-hon-greg-hunt-mp/media/covid-19-whole-of-populationtelehealth-for-patients-general-practice-primary-care-and-other-medicalservices. 
7. Thombs BD, Bonardi O, Rice DB, Boruff JT, Azar M, He C, et al. Curating evidence on mental health during COVID-19: a living systematic review. J Psychosom Res. 2020;110113.

8. Furlong $Y$, Finnie T. Culture counts: the diverse effects of culture and society on mental health amidst COVID-19 outbreak in Australia. Ir J Psychol Med. 2020:1-13.

9. Gunnell D, Appleby L, Arensman E, Hawton K, John A, Kapur N, et al. Suicide risk and prevention during the COVID-19 pandemic. Lancet Psychiatry. 2020;7(6):468-71.

10. Australian Bureau of Statistics. Population clock 2020 [Available from: https://www.abs.gov.au/ausstats/abs\%40.nsf/94713ad445ff1425ca256820001 92af2/1647509ef7e25faaca2568a900154b63?OpenDocument.

11. Australian Bureau of Statistics. 4326.0 - National Survey of Mental Health and Wellbeing: Summary of Results, 20072008 [Available from: https:// www.abs.gov.au/AUSSTATS/abs@.nsf/Lookup/4326.0Main+Features32 007?OpenDocument.

12. Huang Y, Zhao N. Generalized anxiety disorder, depressive symptoms and sleep quality during COVID-19 epidemic in China: a web-based crosssectional survey. medRxiv. 2020;In Press.

13. Cai H, Tu B, Ma J, Chen L, Fu L, Jiang Y, et al. Psychological Impact and Coping Strategies of Frontline Medical Staff in Hunan Between January and March 2020 During the outbreak of coronavirus disease 2019 (COVID-19) in Hubei, China. Med Sci Monit. 2020:26.

14. Wang C, Pan R, Wan X, Tan Y, Xu L, Ho CS, et al. Immediate Psychological Responses and Associated Factors during the Initial Stage of the 2019 Coronavirus disease (COVID-19) epidemic among the general population in China. Int J Environ Res Public Health. 2020:17(5).

15. Kang L, Ma S, Chen M, Yang J, Wang Y, Li R, et al. Impact on mental health and perceptions of psychological care among medical and nursing staff in Wuhan during the 2019 novel coronavirus disease outbreak: A crosssectional study. Brain, Behavior, and Immunity. 2020;In Press.

16. Furukawa TA, Kessler RC, Slade T, Andrews G. The performance of the K6 and K10 screening scales for psychological distress in the Australian National Survey of mental health and well-being. Psychol Med. 2003;33(2):357-62.

17. Ahorsu DK, Lin CY, Imani V, Saffari M, Griffiths MD, Pakpour AH. The fear of COVID-19 scale: development and initial validation. Int J Ment Health Addict. 2020:1-9.

18. Sinclair VG, Wallston KA. The development and psychometric evaluation of the brief resilient coping scale. Assessment. 2004;11(1):94-101.

19. Kessler RC, Andrews G, Colpe LJ, Hiripi E, Mroczek DK, Normand SL, et al. Short screening scales to monitor population prevalences and trends in non-specific psychological distress. Psychol Med. 2002;32(6):959-76.

20. Enticott JC, Lin E, Shawyer F, Russell G, Inder B, Patten S, et al. Prevalence of psychological distress: how do Australia and Canada compare? Aust N Z J Psychiatry. 2018;52(3):227-38.

21. Bitan DT, Grossman-Giron A, Bloch Y, Mayer Y, Shiffman N, Shlomo M. Fear of COVID-19 scale: Psychometric characteristics, reliability and validity in the Israeli population. Psychiatry Res. 2020;289:113100.

22. Winter T, Riordan BC, Pakpour AH, Griffiths MD, Mason A, Poulgrain JW, et al. Evaluation of the English version of the fear of COVID-19 scale and its relationship with behavior change and political beliefs. Int J Ment Health Addict. 2020:1-11.

23. Kocalevent RD, Zenger M, Hinz A, Klapp B, Brahler E. Resilient coping in the general population: standardization of the brief resilient coping scale (BRCS). Health Qual Life Outcomes. 2017:15(1):251.

24. López-Pina J-A, Meseguer-Henarejos A-B, Gascón-Cánovas J-J, NavarroVillalba D-J, Sinclair VG, Wallston KA. Measurement properties of the brief resilient coping scale in patients with systemic lupus erythematosus using rasch analysis. Health Qual Life Outcomes. 2016;14(1):128.

25. Hall RC, Hall RC, Chapman MJ. The 1995 Kikwit Ebola outbreak: lessons hospitals and physicians can apply to future viral epidemics. Gen Hosp Psychiatry. 2008;30(5):446-52.

26. Smith L, Jacob L, Yakkundi A, McDermott D, Armstrong NC, Barnett Y, et al. Correlates of symptoms of anxiety and depression and mental wellbeing associated with COVID-19: a cross-sectional study of UK-based respondents. Psychiatry Res. 2020;291:113138.

27. Australian Bureau of Statistics. 4940.0 - Household Impacts of COVID-19 Survey, 24-2920202020 [Available from: https://www.abs.gov.au/ausstats/ abs@.nsf/mf/4940.0.

28. Black Dog Institute. Mental Health Ramifications of COVID-19: The Australian context. 2020
29. Coronavirus Disease 2019 (COVID-19): Epidemiology, Pathogenesis, Diagnosis, and Therapeutics. Saxena SK, editor. Lucknow, India: Springer; 2020.

30. Pappa S, Ntella V, Giannakas T, Giannakoulis VG, Papoutsi E, Katsaounou P. Prevalence of depression, anxiety, and insomnia among healthcare workers during the COVID-19 pandemic: a systematic review and meta-analysis. Brain Behav Immun. 2020.

31. Muller AE, Hafstad EV, Himmels JPW, Smedslund G, Flottorp S, Stensland SO, et al. The mental health impact of the covid-19 pandemic on healthcare workers, and interventions to help them: a rapid systematic review. Psychiatry Res. 2020;293:113441.

32. Guan WJ, Ni ZY, Hu Y, Liang WH, Ou CQ, He JX, et al. Clinical characteristics of coronavirus disease 2019 in China. N Engl J Med. 2020;382(18):1708-20.

33. Walsh K, Elliott JC, Shmulewitz D, Aharonovich E, Strous R, Frisch A, et al. Trauma exposure, posttraumatic stress disorder and risk for alcohol, nicotine, and marijuana dependence in Israel. Compr Psychiatry. 2014;55(3):621-30.

34. Rodriguez LM, Litt DM, Stewart SH. Drinking to cope with the pandemic: the unique associations of COVID-19-related perceived threat and psychological distress to drinking behaviors in American men and women. Addict Behav. 2020;110:106532.

35. Khantzian EJ. The self-medication hypothesis of substance use disorders: a reconsideration and recent applications. Harv Rev Psychiatry. 1997;4(5): 231-44.

36. Rehm J, Kilian C, Ferreira-Borges C, Jernigan D, Monteiro M, Parry CDH, et al. Alcohol use in times of the COVID 19: implications for monitoring and policy. Drug Alcohol Rev. 2020;39(4):301-4.

37. Yach D. Tobacco use patterns in five countries during the COVID-19 lockdown. Nicotine Tob Res. 2020.

38. Knell G, Robertson MC, Dooley EE, Burford K, Mendez KS. Health Behavior Changes During COVID-19 Pandemic and Subsequent "Stay-at-Home" Orders. Int J Environ Res Public Health. 2020; 17(17).

39. Qiu J, Shen B, Zhao M, Wang Z, Xie B, Xu Y. A nationwide survey of psychological distress among Chinese people in the COVID-19 epidemic: implications and policy recommendations. Gen Psychiatr. 2020;33(2): e100213.

40. Gausman J, Langer A. Sex and gender disparities in the COVID-19 pandemic. J Women's Health (Larchmt). 2020;29(4):465-6.

41. French MT, Mortensen K, Timming AR. Psychological distress and coronavirus fears during the initial phase of the COVID-19 pandemic in the United States. J Ment Health Policy Econ. 2020;23(3):93-100.

42. Langer A, Meleis A, Knaul FM, Atun R, Aran M, Arreola-Ornelas H, et al. Women and health: the key for sustainable development. Lancet. 2015; 386(9999):1165-210.

43. Clay JM, Parker MO. Alcohol use and misuse during the COVID-19 pandemic: a potential public health crisis? Lancet Public Health. 2020;5(5): e259.

44. Biddle N, Edwards B, Gray M, Sollis K. Hardship, distress, and resilience: The initial impacts of COVID-19 in Australia. The ANU Centre for Social Research and Methods; 2020 Apr-2020.

45. International Labor Organization (ILO). Almost 25 million jobs could be lost worldwide as a result of COVID-19, says ILO 2020 [Available from: https:// www.ilo.org/global/about-the-ilo/newsroom/news/WCMS_738742/lang\%2 D\%2Den/index.htm.

46. Services Australia: Australian Government. JobSeeker Payment 2020 [Available from: https://www.servicesaustralia.gov.au/individuals/services/ centrelink/jobseeker-payment.

47. Government ATOA. JobKeeper Payment 2020 [Available from: https://www. ato.gov.au/General/JobKeeper-Payment/.

48. Australian Bureau of Statistics. 3105.0.65.001 - Australian Historical Population Statistics, 20162019 [Available from: https://www.abs.gov.au/ AUSSTATS/abs@.nsf/DetailsPage/3105.0.65.0012016?OpenDocument.

49. Young AF, Dobson AJ, Byles JE. Determinants of general practitioner use among women in Australia. Soc Sci Med. 2001;53(12):1641-51.

50. Australian Institute of Health and Welfare (AlHW). 2.3 Who is in the health workforce? Canberra: AlHW; 2018.

51. Ornell F, Schuch JB, Sordi AO, Kessler FHP. "pandemic fear" and COVID-19. mental health burden and strategies. Braz J Psychiatry. 2020:42(3):232-5.

\section{Publisher's Note}

Springer Nature remains neutral with regard to jurisdictional claims in published maps and institutional affiliations. 